\title{
Dynamic capabilities for the creation of logistics flexibility: a conceptual framework
}

Erik Sandberg

The self-archived postprint version of this journal article is available at Linköping University Institutional Repository (DiVA):

http:/ / urn.kb.se/ resolve?urn=urn:nbn:se:liu:diva- 175363

N.B.: When citing this work, cite the original publication.

Sandberg, E., (2021), Dynamic capabilities for the creation of logistics flexibility: a conceptual framework, International J ournal of Logistics Management, 32(2), 696-714.

https:// doi.org/ 10.1108/ IJ LM-07-2020-0266

Original publication available at:

https:/ / doi.org/ 10.1108/ IJ LM-07-2020-0266

Copyright: Emerald

http:// www.emeraldinsight.com/ 


\title{
Dynamic capabilities for the creation of logistics flexibility - A conceptual framework
}

\begin{abstract}
Purpose: The purpose of this research is to develop a conceptual framework in which dynamic capabilities (DCs) for the creation of logistics flexibility are outlined, and elaborate it further based on empirical data from a case study at a Swedish fast fashion retailer.
\end{abstract}

Design/ methodology/approach: A conceptual framework that aims to delineate the relationship between generic classes of DCs and logistics flexibility is proposed. Thereafter, based on a theory elaboration approach, empirical data from a case study at a Swedish fast fashion retailer is used to identify more specific DCs and further outline the characteristics of the DCs classes.

Findings: The proposed framework draws on the three DC classes of sensing, seizing and reconfiguring, and how they underscore logistics range and logistics response flexibility. The framework also distinguishes between DC classes and logistics flexibility that occur at operational, structural and strategic levels. DCs for the creation of logistics flexibility at a Swedish fast fashion retailer have also been identified and described as a means to further elaborate the characteristics of the DC classes.

Originality: The establishment of a more detailed DC lens, in which different classes of DCs are included, means that an improved understanding for how flexibility is created can be achieved. It helps the research to move beyond the "here and now" existence of logistics flexibility to instead focus on how logistics flexibility can be created.

Research limitations/ implications: Current empirical data is limited to one specific company context.

Practical implications: The research presents a systematic and comprehensive map of different DCs that underscore logistics flexibility, a useful tool supporting logistics development efforts regarding flexibility.

Keywords: Logistics flexibility; supply chain flexibility; dynamic capabilities; retail; fashion

Article classification: Research paper

\section{Introduction}

In today's era of turbulence and a rapidly changing business landscape, companies need to continuously develop and adapt their supply chain practices to fulfil customer requirements and maintain competitiveness (Christopher \& Holweg, 2011). In an uncertain environment, companies face logistics and supply chain challenges due to various trends and changes such as disruptions, technological development and altering consumer behaviour (Manders et al., 2017). To cope with these challenges, logistics flexibility is an essential ingredient, typically defined as the "ability to align, adapt and adjust the process of the goods flow including the inbound and outbound activities and the storage of the goods to the changing customers' needs" (Manders et al., 2017, p. 1009). From a focal 
company perspective, it hence covers a wide range of activities related to the physical flow of goods internally as well as upstream and downstream in the supply chain, with the objective of maintaining customer satisfaction (Jafari, 2015).

Flexibility has received substantial research interest among logistics and supply chain management (SCM) scholars and a number of literature reviews on logistics flexibility, as well as other overlapping concepts such as supply chain flexibility, exist (Jafari, 2015; Tiwari et al., 2015; Manders et al., 2017; Stevenson \& Spring, 2007; Gligor \& Holcomb, 2012; Sharma et al., 2017; Fayezi et al., 2017). For instance, attention and valuable insights have been directed towards descriptive publications on statistics in the field, definitions, types of flexibility, and operational capabilities required for flexibility performance. Current understanding of flexibility in the logistics research field is normally grounded in an expansion of internally oriented manufacturing flexibility research (Liao, 2020; Huo et al., 2018; Blome et al., 2013).

As a means to complement the manufacturing-centred research, and at the same time strengthen the theoretical underpinning of the flexibility concept, a dynamic capabilities view (DCV) has increasingly been applied in flexibility research (Manders et al., 2017; Rojo et al., 2018). Dynamic capabilities (DCs) are typically defined as "the capacity of an organization to purposefully create, extend, or modify its resource base" (Helfat et al. 2007 , p. 4). In a similar manner as for flexibility, DCs are acknowledged as a means to cope with changes in the environment to sustain competitive advantage. Examples of previous work that combines DCs with flexibility in a logistics and SCM setting include Chiang et al. (2012) who investigated how strategic sourcing underscored agility as a firm's dynamic capability, Griffith et al. (2006) who suggested market responsiveness to be a dynamic capability, and Kim et al. (2013) who applied a DCV when investigating the relationship between market flexibility and supply chain responsiveness. A common rationale for these examples is that the application of a DCV offers a valuable lens for the exploration of what actually underscores creation of flexibility (Swafford et al., 2006; Rojo et al., 2018; Gligor \& Holcomb, 2014). By focusing on the DCs involved in the creation of flexibility, researchers are enabled to move beyond the "here and now" existence of flexibility to instead focus on how flexibility can be achieved.

Although identification of factors that determine and influence flexibility have been highlighted as critical, and the fact that a DCV is often presented as a promising theoretical lens for understanding these factors (e.g. Gligor \& Holcomb, 2014; Blome et al., 2013), research on the actual DCs that underscore flexibility is still in its infancy. To advance research in this area, the premise of this research is need to systematically relate the two concepts of DCs and flexibility to each other in a more detailed manner. This is particularly built upon the notion that whereas existing research on flexibility offers a large number of classifications of flexibility, specific types of DCs and their respective role in the creation of flexibility are so far poorly examined. Establishing a more detailed DC lens, in which different classes of DCs are included, means that an improved understanding for how flexibility is created can be achieved.

The purpose of this paper is therefore to (1) develop a conceptual framework in which dynamic capability classes for the creation of logistics flexibility are outlined, and (2) elaborate it further based on empirical data from a case study at a Swedish fast fashion retailer. The proposed framework draws on Teece's (2007) three seminal dynamic capability classes of sensing, seizing and reconfiguring, and how they relate to logistics flexibility as captured here in the two dimensions of range and response flexibility. The 
framework also distinguishes between DCs and logistics flexibility that occur at operational, structural and strategic levels. As such, the framework seeks to create a holistic view of the classes of DCs involved in the creation of logistics flexibility. To limit the complexity, and align it with Teece's (2007) framework, the research takes a focal company perspective on logistics flexibility. To further elaborate characteristics of the DC classes involved, the framework is applied to empirical data from a case study at a Swedish fast fashion retailer. The case study here represents an interesting, information-rich case concerning a company that operates in an industry with a high pace of change and major challenges such as omnichannel development and complex, global logistics operations, and is thus in need of logistics flexibility.

The remainder of this article outlines methodology (ch. 2) and an overview of the logistics flexibility concept and the DCV (ch. 3). Based on these two theoretical starting points, an overall conceptual framework is developed (ch. 4). Thereafter specific DCs for logistics flexibility at the case company are presented, based on the structure provided by the conceptual framework (ch. 5). Finally, theoretical and practical implications are discussed and suggestions for future research are outlined (ch. 6).

\section{Methodology}

This research is based on a theory elaboration approach (Ketokivi \& Choi, 2014). Such an approach is applicable when the research objective is not primarily to test a general theory, nor generate a brand new, but to elaborate and contextualise an existing one. This is, for instance, a valuable approach when relationships among constructs need to be further detailed (Ketokivi \& Choi, 2014), which is the aim of this research. Thus, guided by a general theoretical logic, in combination with empirical data findings, a theory elaboration approach typically clarifies, or even modifies, a general theory in order to reconcile it with contextual factors (Ketokivi \& Choi, 2014).

In this research, the general theory is presented as a generic framework in which the DC classes of sensing, seizing and reconfiguring are related to range and response flexibility (see section 4). In Maclnnis' (2011) terminology for different types of conceptual contributions, the proposed framework is based on a deductive reasoning that aims to delineate the relationship between DCs and logistics flexibility. Such framework emphasises and attempts to explain the relationship among constructs. Metaphorically, it could be considered as a map outlining the logic between the constructs (Macl nnis, 2011). The case study presented in this research offers an opportunity for further elaboration of this map. Specific DCs in each DC class, at different hierarchical levels, are identified. Furthermore, based on these, the characteristics of the different DC classes in the framework are elaborated.

\subsection{The conceptual framework development}

Covering and summarising the entire body of research regarding flexibility and DCs is a challenging research task given the amount of research provided, even if it is narrowed down to literature solely relevant from a logistics and SCM point of view. However, the combination of the two strands of literature is much less explored. For such circumstances, where the aim is to enhance knowledge based on a combination of different literature bodies, and when the targeted outcome is e.g. a new framework, an integrative literature review approach is suitable (Torraco, 2016; Snyder, 2019). 
In the light of the purpose of this study, the strategy for the integrative literature review has been to take recent existing literature reviews on logistics and supply chain flexibility as a starting point (Jafari, 2015; Manders et al., 2017; Tiwari et al., 2015; Gligor \& Holcomb, 2012; Sharma et al., 2017; Fayezi et al., 2017) and from these conduct a backward as well as forward snowball approach (Wohlin, 2014) to identify further relevant literature. The aim has been to capture how capabilities, and especially DCs, are related to flexibility in previous research. In addition, a variety of search strings in the Scopus and Business Source Premier databases have also been constructed, based on "dynamic capabilities" and "flexibility", and other relevant terms such as "agility", "responsiveness" etc. Particular attention has been given to the term "logistics flexibility" and "supply chain flexibility". In contrast to a systematic literature review, the aim of an integrative literature review is not to cover the full range of existing research, but rather to synthesise literature in a way that lays the foundation for new theoretical frameworks (Snyder, 2019).

For this synthetisation, the principles of open, axial and selective coding have guided the analysis (Wolfswinkel et al., 2013). Among the plethora of different concepts and typologies that exist in the two strands of literature, the open and axial coding revealed three major building blocks during the literature review that were further elaborated: (1) the subcategories of range and response flexibility, (2) the hierarchical presence of strategic, structural and operational flexibility levels, and (3) the three DC classes of sensing, seizing and reconfiguring. Together these three building blocks were found to enable a comprehensive, yet detailed framework that captures the relationship between DCs and logistics flexibility in a new way. Selective coding was thereafter conducted, in an iterative process (Wolfswinkel et al., 2013), to further describe and illuminate the relationship between the categories (Torraco, 2016; Wolfswinkel et al., 2013) until a saturation point was achieved, i.e. new information from the reviewed articles did not contain any new relevant information regarding the relationship between the categories (Wolfswinkel et al., 2013).

\subsection{The case study}

To further elaborate the DC classes included in the conceptual model, it was applied to empirical data from a case study at a Swedish fast fashion retailer. In line with a theory elaboration approach, the major objective with the case study has been to enable more detailed characteristics of the involved DC classes of sensing, seizing and reconfiguring. Thus, the empirical data does not seek to test or verify the existence of DC classes, but rather to elaborate their content.

The fast fashion industry is well-known for its high pace of change due to its characteristics of rapidly changing customer requirements, short lifecycles and fierce competition (Christopher et al., 2004, Wen et al., 2019). To cope with the many uncertainties in the global and complex fast fashion supply chains, logistics flexibility is an essential ingredient for sustainable competitive advantage, not the least from a retailer's point of view. The case company presented in this study therefore represents a valuable, information-rich case study (Flyvbjerg, 2006) with respect to the DCs that underscore logistics flexibility.

The data collection has been conducted within a larger research project based on an action research approach (Coughlan \& Coughlan, 2002; Näslund et al., 2010). Action-based research is typically characterised as an interactive and participative research approach, in which researchers and practitioners collaborate to solve a social or organisational problem 
or challenge (Coughlan \& Coughlan, 2002). It is especially useful for the understanding, planning and implementation of change processes (Coughlan \& Coughlan, 2002). With the overall objective of improving logistics development practices at the company, the researchers have followed two specific development initiatives at the company, targeting global omnichannel design and the transformation towards customer-driven logistics operations throughout the supply chain. The content in these two projects provides a rich data set with respect to DCs involved in the creation of logistics flexibility.

For a period of eight months, on average once every second week, the researchers have participated in a variety of project meetings together with staff mainly employed by the departments of business development and/or supply chain operations. During these meetings, the researchers have followed the work, but also provided academic input and comments on the development work, thus the objective of the research project has been to simultaneously take action to solve a problem at a company and create knowledge (or theory) about that action (Coughlan \& Coughlan, 2002). In addition, the researchers have also held a series of discussions and unstructured interviews with some of the project participants, as a means to further enhance the researchers' understanding of the case company's situation and the development projects. These discussions have been especially important as a means to improve the credibility and dependability of the research, i.e. internal validity and reliability (Halldorsson \& Aastrup, 2003), as researchers here have been able to pose more detailed questions and reflect together with the interviewees. Moreover, some of the project participants have read the researchers' research results at various stages in the research process, including the research presented in this particular paper. Altogether, these activities have ensured triangulation of data, ensuring validity as well as reliability of the study (Näslund et al., 2010).

As a means to create a transparent "chain of evidence" between the empirical data and the presented findings, ensuring confirmability (Halldorsson \& Aastrup, 2003), the researchers have continuously kept a journal (Coughlan \& Coughlan, 2002; Näslund et al., 2010), taking notes on the progress and knowledge learned in the development projects being followed. These notes have also been coded in a pattern-matching manner (Näslund et al., 2010) against the theoretically derived framework presented in section 4. For each of the DC classes in the framework, specific DCs have been identified and described (see section 5.1-5.3). Although the objective of the study was not to produce an exhaustive list of DCs, all major DCs relevant for the creation of flexibility were deemed to have been identified after a period of eight months. In a subsequent step, characteristics of these DCs were summarised as a means to further elaborate and detail the DC classes in the framework (see section 5.4).

\section{Theoretical framework}

The conceptual framework developed in this research is based on a combination of the concept of logistics flexibility and a DCV, in particular its three dynamic capability classes of sensing, seizing and reconfiguring that were first outlined by Teece (2007).

\subsection{Logistics flexibility}

The concept of flexibility has been elaborated and defined in numerous ways in research and treated in a variety of research contexts, including strategic management (Teece et al., 2016), organisational research (Volberda, 1996; 1998; Van der Weert et al., 2012), 
manufacturing and operations management (Singh, 2013; Slack, 1987; 2005), and logistics and SCM (J afari, 2015; Tiwari et al., 2015). Accordingly, flexibility literature has applied a number of prefix terms such as "organisational", "manufacturing" or "supply chain". Moreover, flexibility issues have been extensively researched in terms of other concepts such as agility and responsiveness (Christopher et al., 2004; Holweg, 2005; Sandberg \& J afari, 2018; Reichhart \& Holweg, 2007; Sharma et al, 2017).

Flexibility has been most researched within the realms of manufacturing and operations management of a company (J afari, 2015; Tiwari et al., 2015; Stevenson \& Spring, 2007). Important factors for creating manufacturing-based flexibility are for instance the equipment, control systems, work force and suppliers of the production system (Olhager, 1993). These factors contribute to pivotal flexibility types such as volume and mix flexibility. Within manufacturing, these types have been investigated and defined in several ways. Whereas mix flexibility mainly refers to the ability to produce a wider range of different products, the volume flexibility refers to the ability of handling changes in the aggregated production output volumes (e.g. Slack, 1987; Gerwin, 1993). Additionally, the ability of changing the design of a specific product, i.e. product flexibility, is another common flexibility type in a manufacturing context (e.g. Olhager, 1993; Slack, 1987).

The notion of flexibility has also been established outside an internal manufacturing domain (Tiwari et al., 2015; Huo et al., 2018; Stevenson \& Spring, 2007; Manders et al., 2017; Liao, 2020), and it is mainly in this extended environment, beyond the manufacturing function, that logistics flexibility becomes relevant. Logistics flexibility is here understood to be concerned with a focal company's internal flow of goods, as well as external upstream and downstream flows. It includes the components of physical supply, as well as distribution (including warehousing) at a focal company, along with its purchasing and demand management activities (Jafari, 2015; Stevenson \& Spring, 2007; Zhang et al., 2005; Zhang et al., 2002), see Table 1 below.

Table 1: Components of logistics flexibility (adapted from J afari, 2015, p. 950)

\begin{tabular}{|l|l|}
\hline Flexibility component & Description \\
\hline Physical supply flexibility & $\begin{array}{l}\text { the ability to provide a variety of inbound transportation, } \\
\text { warehousing, and material inventory quickly and accurately. It } \\
\text { enables firms to coordinate the delivery of incoming goods. }\end{array}$ \\
\hline Physical distribution flexibility & $\begin{array}{l}\text { the ability to adjust inventory, packaging, warehousing, and } \\
\text { transportation of physical products quickly to meet customer } \\
\text { needs. It deals with delivering the finished product to customers } \\
\text { reliably and efficiently. }\end{array}$ \\
\hline Purchasing flexibility & $\begin{array}{l}\text { the ability to provide the variety of materials and supplies } \\
\text { quickly and performance-effectively through cooperative } \\
\text { relationships with suppliers. This requires a heavy emphasis on } \\
\text { information exchange and mandates effective and frequent } \\
\text { communication with supplier. }\end{array}$ \\
\hline Demand management flexibility & $\begin{array}{l}\text { the ability to respond quickly and performance- effectively to } \\
\text { the variety of customer needs in terms of ordertaking, delivery } \\
\text { scheduling, installation, repair, training, and product } \\
\text { maintenance. It facilitates communication with customers. }\end{array}$ \\
\hline
\end{tabular}




\subsubsection{Dimensions of flexibility}

Slack (1987) identified range and response flexibility as two fundamental dimensions of flexibility, which have since been referred to and applied in a variety of flexibility research settings (Slack, 2005;). Range flexibility corresponds to the total number of states or outcomes that the organisation or a specific resource is able to achieve. For instance, in a manufacturing context, a production system is typically considered to have a higher rate of range flexibility when it is able to handle a greater range of volumes (Gerwin, 1993). Its emphasis is on the ability to change, as opposed to an actual change activity (Upton, 1994). The range dimension has later been further detailed into range-number and rangeheterogeneity, pointing out that the actual number of possible options, as well as the extent to which the different options distinguish from each other, defines range flexibility (Koste et al., 2004; Upton, 1994). Response flexibility corresponds to the ease (measured in costs, time or a combination of these) with which changes can be made within the range. This dimension has also been further refined in research. Similar to Slack's original definition, Upton (1994) labels this dimension mobility, occupied with the costs and time associated with changes within the range, so-called transition penalties. Strongly related to manufacturing, another dimension discussed is uniformity, which is mainly concerned with maintaining product quality when shifting products (Zhang et al., 2005), i.e. when changing state within the flexibility range, a possible variation in terms of performance must be taken into consideration (Koste et al., 2004; Upton, 1994; Zhang et al., 2002).

Although the two dimensions of range and response flexibility originate from a manufacturing context, their application is universal (Slack, 2005; Bernardes \& Hanna, 2009). Together, they capture both the capacity to develop alternative options, as well as the processes to achieve a specific state (Huo et al., 2018), e.g. outlined as scope and achievability by Koste et al. (2004). In organisational flexibility research, a similar view is taken when it is argued that variety as well as speed must be accomplished (Volberda, 1996). In fact, the combination of range and response dimensions can be observed in many pieces of flexibility research (Koste et al., 2004; Liao, 2020; Stevenson \& Spring, 2007; Holweg \& Reichhart, 2007). For instance, Swafford et al. (2006) build on Slack's original understanding and in their research on supply chain agility apply the flexibility dimensions of range and adaptability, the latter very similar to Slack's (1987) understanding of response flexibility. Liao (2020) claims that logistics flexibility is required in the short term to enhance responsive physical connections throughout the supply chain, and, in the long term, to provide new solutions for inbound and outbound logistics. Logistics flexibility hence consists of a combination of a range as well as a response dimension.

\subsubsection{Flexibility at different hierarchical levels}

Flexibility could occur at different hierarchical levels in a company, ranging from operational to strategic level (Manders et al., 2017; Stevenson \& Spring, 2007; Upton, 1994; I vanov et al., 2018). Organisational research (Volberda, 1996; 1998; Van der Weert et al., 2012), has suggested that from a focal company perspective, flexibility spans the three levels of operational, structural and strategic flexibility. Strategic flexibility refers to a "strategic manoeuvring capacity" (Volberda, 1998) that involves fundamental changes in the norms and values of the company. It is typically characterised as qualitative, unstructured and nonroutine (Volberda, 1996; 1998). As such, it challenges the existing strategies, business model and behaviour of the company, and includes strategic business moves such as repositioning in the market and application of new technology (Volberda, 1998; van der Weert et al., 2012), with the purpose of sustaining a company's competitive advantage (Singh et al., 2013). In a supply chain setting, strategic flexibility could embrace 
issues related to e.g. introduction of new products, expansion of long-term supply chain capacity and adapting to changes in the market (Stevenson \& Spring, 2007).

Structural flexibility refers to flexibility in the organisational structure, including its decision and communication processes (Volberda, 1996; van der Weerdt et al., 2012). The organisation and the supply chain design hence become the tool for how to achieve structural flexibility. Some activities to achieve structural flexibility in a supply chain context are put forward by Christopher \& Holweg (2011), who argue that dual sourcing, asset sharing, separation of base and surge demand, postponement, flexible labour arrangements, rapid manufacture and outsourcing are all strategies for the achievement of structural flexibility.

Operational flexibility emanates from the ability to efficiently handle expected, familiar changes in activities conducted in the company (Volberda, 1996). The objective of operational flexibility is geared towards efficiency (as opposed to effectiveness) and the reduction of different types of operational risks that exist in the environment (van der Weerdt et al., 2012). Operational flexibility is mainly reactive and often embedded in predefined rules and routines (Volberda, 1996). In a supply chain setting, operational flexibility is captured in Christopher \& Holweg's (2011) understanding of "dynamic flexibility", which "allows firms to cope with certain shifts in demand and technology, but only within the set structure of their existing supply chain design" (Christopher \& Holweg, 2011 , p. 64). The objective here is to reduce cost through increased control, which is possible in a fairly stable supply chain environment.

\subsection{Dynamic capabilities}

The overall premise of a DCV is that a sustainable competitive advantage is accomplished by the creation, extension and modification of the underlying resource base (Helfat et al., 2007). Especially in business environments characterised by their high degree of risks and uncertainties in terms of customers, competitors and new technologies, there is a need for appropriate DCs (Teece et al., 2016). DCs are considered to be embedded in organisational and managerial processes or routines, concerned with actual changes of the resource base. However, the content of DCs has expanded during the years of development to become more of a multidimensional construct (Barreto, 2010). For instance, as DCs sometimes seek to manage the "unknown unknowns" (Teece et al., 2016), DCs may also contain an entrepreneurial component, in which finding new ways to operate is emphasised. Such a component is less routinised and repeatable than the original understanding of DCs as was presented in e.g. Teece et al. (1997) and Eisenhardt \& Martin's (2000) seminal articles. In addition, except for the change processes and routines themselves, an important component of dynamic capabilities is considered to be the sensing of business opportunities and threats (Teece, 2007) and timely and market-oriented decision-making (Barreto, 2010). As such, before the execution of the actual change of the resource base, there is a need to first identify and understand (sense) an opportunity and make the decision to conduct a change. Thus, to incorporate and span these tasks, dynamic capabilities are often understood as a "capacity" or "ability" to change the resource base (see e.g. Helfat et al., 2007; Teece, 2007, Barreto, 2010). To outline such a capacity in more detail, Teece (2007) suggested that DCs can be categorised into the three classes of sensing, reconfiguring and seizing. 
Sensing (and shaping) business opportunities and threats includes a variety of processes aimed at the "discovering" of business opportunities, as well as subsequent analysis and sensemaking processes regarding their potential (Teece, 2007; Teece et al., 2016). Together, these processes constitute an important basis for the seizing and reconfiguring capabilities outlined below. It is essential to discover and analyse business opportunities early, ahead of competitors, before they materialise (Teece et al., 2016). To achieve this, effective environmental scanning processes are required to absorb trends external to the company, as well as internal events that bring relevant information regarding future potential business opportunities. The scanning processes have long been recognised as an important element of organisational change, including formal as well as informal processes (Hambrick, 1982). In the realm of logistics and SCM, scanning processes such as forecasting processes and the use of point of sales data are vital for "market sensitivity" in agile supply chains (Christopher et al., 2004). So is the use of relevant key performance indicators to ensure customer satisfaction (Mentzer et al., 2001). The sensed business opportunities must subsequently also be shaped, i.e. analysed in relation to e.g. technologies to pursue and market segments to target. An understanding of how surrounding competitors, suppliers and customers will act must also be attained, for instance through scenario planning (Teece et al., 2016). The planning of logistics activities throughout the supply chain and development and analysis of supply chain strategies are here essential ingredients of such a shaping.

Managing and reconfiguring threats includes the incremental as well as radical orchestration of tangible as well as intangible resources, internally as well as externally to the company (Teece, 2007). The objective is to adapt the resource base to changing customer and technology developments, but also to shape the market and ecosystem in which it operates (Teece, 2007), i.e. an evolutionary fitness is searched for (Helfat et al., 2007; Teece, 2007). From a managerial perspective, continuous development of operations and related learning is essential, meanwhile efficiency in the present activities is required. Thus, an act of balance between exploration and exploitation (March, 1991) is inherent in the reconfiguring capability (Teece, 2007). In a logistics and SCM context, the physical flow of goods constitutes an important component of the resource base that is subject to reconfiguring capabilities. Liao (2020) notes that reconfiguration of the supply chain is a critical capability for supply chain flexibility, as a high level of this flexibility can accommodate more uncertainties related to product delivery, mix and volume of customer demands. As eliminating all uncertainties in the supply chain is impossible, there is a need to meet them with adequate range flexibility, and thus appropriate reconfiguring capabilities are needed (Liao, 2020).

Seizing business opportunities is, according to Teece et al. (2016), about "implementation and getting things done" (Teece et al., 2016, p. 22), i.e. when a business opportunity is sensed, it must also be seized (Teece, 2007). Overall, seizing processes are concerned with the development and commercialisation of new processes, products and services. These processes stretch from the management of initial, competing potential solutions, via analysis and decision-making where potential development paths are narrowed down, to the final launch of a new process, product or service. They include the selection or development of appropriate business models, as well as managerial decision-making along the different development stages (Teece, 2007; Barreto, 2010). In a logistics and supply chain setting, seizing capabilities has been emphasised for the rapid and efficient response to customer needs related to delivery, support and other services (Zhang et al., 2005). From a SCM perspective, seizing capabilities could include external partnerships, where 
joint responsibility is taken for implementing strategies to serve differentiated customers in a timely and cost-efficient manner (Liao, 2020). Such supply chain flexibility is based on a "collaborative competence", in which collaboration and coordination with supply chain partners is decisive (Huo et al., 2018).

\section{A framework of dynamic capabilities for the creation of logistics flexibility}

Flexibility and the DCV are clearly interrelated concepts. For instance, flexibility or similar terms such as agility could be highlighted as a dynamic capability in itself (e.g. Chiang et al., 2012; Blome et al., 2013), or DCs could be considered a necessary prerequisite to achieve flexibility (Singh et al., 2013; Gligor \& Holcomb, 2014). In a similar vein, DCs have been described as the "managerial task" to achieve flexibility (van der Weerdt et al., 2012; Volberda, 1996), i.e. the existence of flexibility is reflected by the presence of DCs in the organisation (Singh et al., 2013). As a means to improve the understanding for how the two concepts are related to each other, the conceptual framework proposed in this research takes a stance in the two flexibility dimensions of range and response flexibility (see Figure 1). As for flexibility in general, these two dimensions are also fundamental in a logistics setting. For instance, an inherent readiness or capacity to face a variety of uncertainties is a well-known criterion for supply chain design (Stevenson \& Spring, 2007). Dual sourcing and outsourcing are here two examples of supply chain strategies aimed at increasing the logistics flexibility range (in conjunction with other objectives such as improved cost efficiencies). For logistics response flexibility, the effective and efficient response to customer requirements is an essential component of logistics performance (Huo et al., 2018). In accordance with previous research, logistics range flexibility is defined as the number of potential states it is possible to achieve in the physical supply and distribution and related purchasing and demand functions. Logistics response flexibility is defined as the ease (measured in logistics performance indicators such as costs, speed, service, environmental impact, etc.) with which changes can be made within the logistics flexibility range.

The point of interaction between the flexibility concept and DCs is in the framework built upon the assumption that the range and response flexibilities are coupled with different DC classes. Logistics range flexibility is enhanced by reconfiguring capabilities, aimed at providing alternative and/or completely new resource configurations in the supply chain. The objective of these configurations is primarily to facilitate a future broad palette of business opportunities and manoeuvring space, e.g. to ensure preparedness for future uncertainties. In the vocabulary of strategic management research, an evolutionary fitness (Helfat et al., 2007) is searched for. Logistics response flexibility, in turn, is enhanced by seizing capabilities that capture business opportunities within the provided logistics flexibility range, i.e. the existing organisational structure and resource base. These capabilities ultimately seek to construct a new supply chain configuration that is better than the previous one. In contrast to reconfiguring, seizing capabilities is concerned with the actual implementation of a new product, process or service, e.g. an accurate response to e.g. changed customer requirements. As a third category of DCs, sensing capabilities that represent the ability to discover and analyse business opportunities and threats is included in the framework as an essential prerequisite for reconfiguring as well as seizing capabilities. 
As emphasised in existing flexibility research, DCs can aid in developing flexibility at several hierarchical levels (Rojo et al., 2018). The framework therefore constitutes three hierarchical levels of flexibility, i.e. a strategic, structural and operational level, as outlined in the previous chapter. Together, these three levels capture the variety of DCs inherent in a company's logistics and SCM operations that result in logistics range and response flexibility.

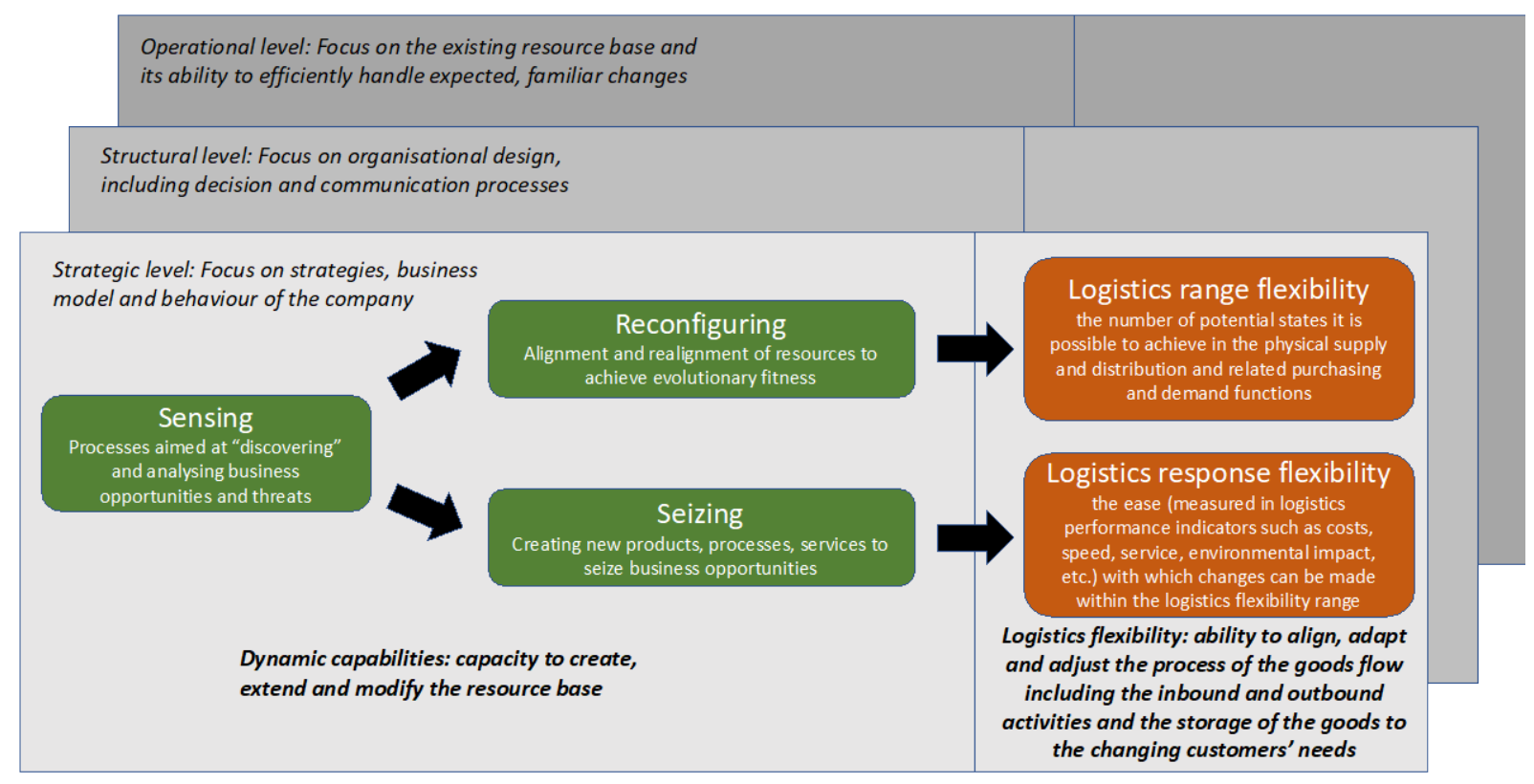

Figure 1: Conceptual framework of DC classes and logistics flexibility

\section{Dynamic capabilities for logistics flexibility - findings from a case study}

Headquartered in Sweden, the case company is today a global concern with customer markets across different continents. It operates a number of fast fashion brands with a variety of characteristics. Whereas design and retailing operations such as logistics, marketing and sales are the major inhouse functions, production is provided by independent manufacturers concentrated in Asia. Logistics-wise, the company orchestrates a complex distribution network with warehouses worldwide. Sales via physical stores is the dominant market channel, but in recent years this has been complemented with various online sales solutions in a number of customer markets. Appropriate, flexible, omnichannel logistics operations are needed, and the entire corporation has therefore increasingly focused its managerial attention on the logistics operations. 


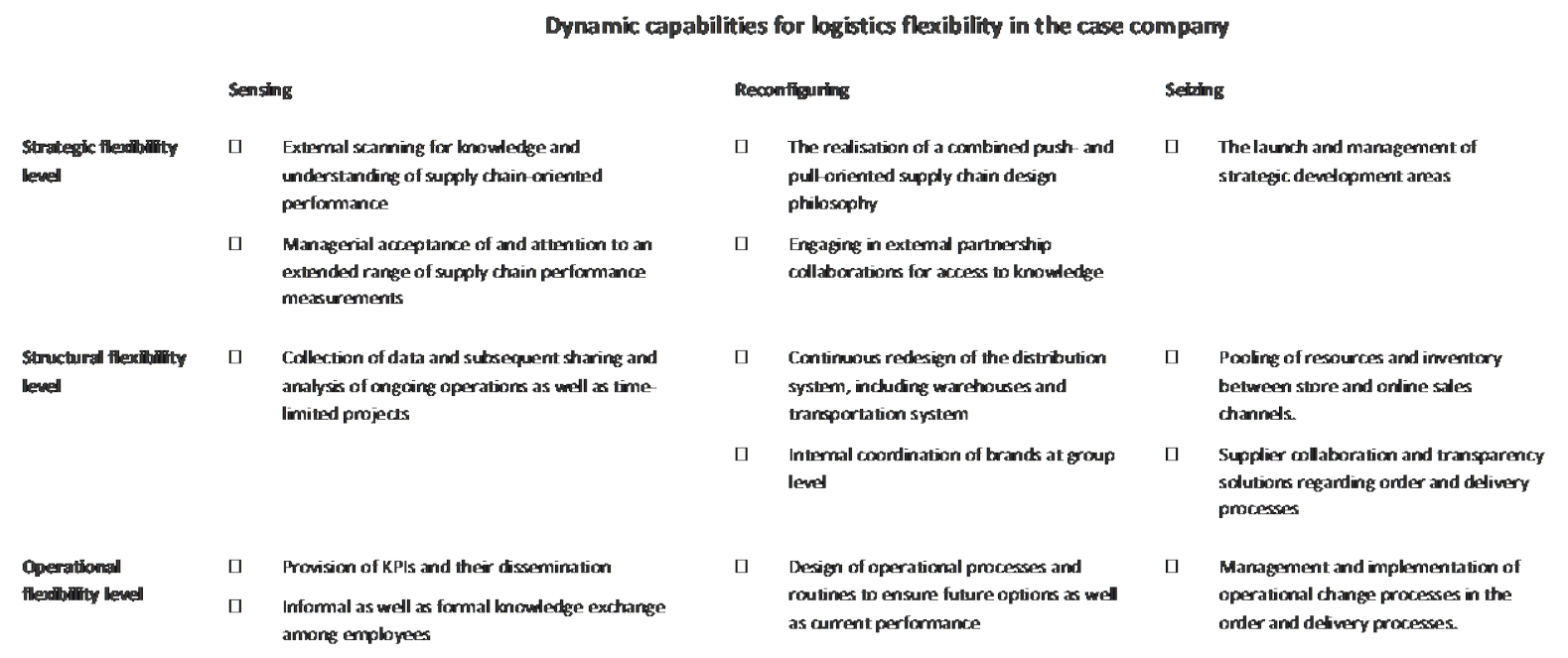

\subsection{DCs at a strategic flexibility level}

In recent years, accompanied by several fundamental shifts in the industry, the retailer has indicated possession of essential strategic sensing capabilities (See Table 2). Overall, the company has developed towards a more inclusive learning culture, in which external knowledge resources increasingly play a role as an input for the retailer's strategic reconfiguring and seizing capabilities. In particular, external scanning of traditional topics such as customer requirements and the effectiveness and efficiency of global manufacturing processes has in recent years been complemented with knowledge capture regarding supply chain integration and the role of logistics in enhancing customer satisfaction. The company has always taken pride in making use of diversity in knowledge and competencies. Now this also encompasses a learning culture in logistics, whereby a narrower focus on product availability and cost structures has been complemented with these new supply chain-oriented perspectives on performance. This also includes managerial acceptance towards an extended range of supply chain performance measurements.

Initiated and supported by its strategic sensing capabilities, the retailer has extended its strategic flexibility range as a result of strategic reconfiguring capabilities. In particular, the company has developed its supply chain design philosophy from being push-oriented to become a hybrid in which push- and pull-oriented strategic planning is continuously combined. Overall, the current supply chain design philosophy is still geared towards the historically dominant push orientation, but has increasingly been complemented with a pull-oriented design when judged suitable. The development towards a hybrid orientation follows a major trend within the entire fast fashion industry (e.g. Wen et al., 2019). Another strategic reconfiguring capability entails the company's development towards increased collaboration with external partners regarding access to knowledge. As a logical extension of their external scanning capability, the company has slowly engaged in more external collaborative partnerships as a means to capture and exploit external knowledge sources. As indicated in previous research, such knowledge accessing (Defee \& Fugate, 2010) facilitates access to appropriate knowledge when needed, thus extending the strategic flexibility range. For instance, close collaboration with universities has resulted in extended access to academic knowledge (as this particular research proves). 
Strategic seizing capabilities for the achievement of strategic response flexibility include, among other things, the launch and management of specific project-based development areas that are geared towards topics identified as especially strategically important (through strategic sensing capabilities). Contemporary development areas at the retailer are focused, for instance, on omnichannel inventory availability improvements and product differentiation efforts regarding order and delivery processes in the global supply chain. These initiatives, which are typically cross-functionally operated with clear sponsorship from top management, constitute an important platform for the generation of new ideas and influences on the company's strategic intentions and goals, but also for the actual testing and fine-tuning of strategic development moves in the supply chain. Thus, in line with Teece's (2007) understanding of a seizing capability, the projects typically span the entire development process from the moment a business opportunity is sensed and analysed, to the launch of a final product, service or process.

\subsection{DCs at a structural flexibility level}

Important structural sensing capabilities include the processes of data collection and subsequent analysis using a wide range of measurements from the retailer's continuous, ongoing global logistics operations. In particular, the capability involves the ability to supply useful data and information to the right receiver in the organisation, as well as appropriate tools and knowledge for the subsequent analysis. Alongside the ongoing operations, structural sensing capabilities are also present in conjunction with the launch and execution of specific pilots, practical tests and other time-limited projects. For instance, the retailer has initiated pilots of various kinds related to new picking and packing processes where the store and online sales channels are integrated. Lessons learned from these tests play a crucial role in the experimental, rapid development of operational practices, as well as strategic decisions regarding warehouse design and their operations in the company.

In a rapidly changing and hazy future environment, structural reconfiguring capabilities for the expansion of a structural range flexibility are vital. For the retailer, such reconfiguring capabilities include the ability to continuously redesign the distribution system to sustain evolutionary fitness (Helfat et al., 2007; Teece, 2007) without closing off too many future design options. The distribution system, which includes the network of warehouses and the transportation system, is considered as the major "toolbox" for ensuring range flexibility in the company's supply chain. This range is maintained primarily by two strategies. First, the retailer has invested in the warehouses' ability to deliver a combination of store and online sales operations. This has led to an increase in combined warehouses, from which the distribution of both store and online sales is being operated, which enables a wider range of design possibilities in terms of e.g. capacity allocation. A second strategy concerns the continuous redesign of the actual number and location of the warehouses. In recent years the objective of the warehouses has shifted from mainly supporting a store-based expansion strategy to instead supporting the retailer's omnichannel offering. The change towards omnichannel fulfilment entails a balancing act between a warehouse presence that is local to the customer market to ensure short lead times, and also requiring regional, centralised warehouses to gain economies of scale and scope in the operations.

As well as the redesign capability, another major structural reconfiguring capability concerns internal coordination among brands in the company. From a logistics point of view, such coordination facilitates structural range flexibility, as it enables an extended palette of logistics options in relation to e.g. new distribution, market and omnichannel 
strategies. In short, improved coordination between brands improves the manoeuvring space of possible logistics strategies and design solutions.

Given the high pace of change in the competitive environment of the retailer, rapid and continuous change to the actual supply chain design is increasingly becoming a priority in the company. For this, structural seizing capabilities are required. A vital logistics-related structural seizing capability at the retailer is the ability to find and implement viable solutions for pooled resources, as well as inventory between the store and online sales channels. This is gradually being made possible with an increased number of physically combined store and online sales warehouses (i.e. part of an increased structural range flexibility). Here, the retailer has recently formulated and adopted global principle guidelines for such an integration, as well as a number of local, market-specific solutions for the actual roll-out at specific warehouses.

The continuous reorganisation of the distribution system also requires structural seizing capabilities with respect to improved supplier collaboration and transparency in the order and delivery processes. For instance, improved dialogue and transparency with manufacturers, in terms of the length of contractual agreements and joint planning over a longer period of time regarding seasonless products, is sought here. Also, at the other end of the product range, collaboration with manufacturers regarding high-fashion products with limited lifecycles is required. In particular, solutions based on supply chain agility with local sourcing and rapid manufacturing principles (e.g. Christopher \& Holweg, 2011) are developed jointly with manufacturers. Overall, efforts regarding supplier collaborations are a sign of the retailer's objective concerning total supply chain performance. In line with a supply chain orientation (Mentzer et al., 2001), the retailer has increasingly expanded its attention to also include the suppliers' part of the supply chain, in order to seize viable business opportunities in the supply chain.

\subsection{DCs at an operational flexibility level}

Operational sensing capabilities at the retailer include the existence of operational Key Performance Indicators (KPIs) that capture existing logistics operations, and the routinised follow up processes and analysis of these. In a large, global organisation such as the retailer, access to basic data and other information is critical for appropriate analysis and decision-making. Another operational sensing capability at the retailer includes the crossfunctional and geographically dispersed information and knowledge exchange, both informal and formal, among employees. Embedded in the corporate culture, such forms of exchange create the basis for appropriate reconfiguring, as well as seizing capabilities.

As the retailer's entire supply chain operates in a global, volatile environment, with fierce competition, development of new operational logistics design is considered a necessity and is well-established throughout the company. Operational reconfiguring capabilities include the design of operational processes and routines that should ensure wide, future-oriented operational range flexibility, while at the same time providing contemporary, efficient and effective daily operations throughout the supply chain. An example is an ongoing, global review of labels with the objective of standardising their content, thus enabling the particular product to end up in a wider range of customer markets. Another example concerns packaging design differences between products aimed at store sales and online sales. A reduction in these differences improves the possibility of the products being sold in both channels. 
The operational seizing capabilities concern the rapid and efficient execution of multiple changes in the operational supply chain design, mainly covering upgrading of processes and routines in the order and delivery process. The management of these operational, often minor, changes targets the retailer's incremental improvements regarding performance on cost, transparency, forecasting, speed, product availability, etc. Examples of operational seizing capabilities at the retailer include the introduction and refinement of last mile delivery options in different markets and the implementation of rule-based reallocation processes for products between markets and warehouses during a season.

\subsection{Characteristics of DCs involved in the creation of logistics flexibility}

The DCs presented above (Table 2 ) indicate the existence of a variety of more specific DCs that are all significant for the creation of logistics flexibility in the case company. Some common characteristics of these DCs are outlined in the following paragraphs.

At a strategic level, the sensing capabilities observed are mainly characterised by their focus on external information and knowledge capture outside the "traditional" logistics domain. Business opportunities beyond this domain are increasingly sensed, with an emphasis on opportunities for the entire supply chain, and often linked to overall customer satisfaction. In this widened scope, information and knowledge capturing processes feed reconfiguring and seizing capabilities in the form of collaboration with parties outside the logistics domain, within the company but also with external supply chain members. In collaboration with other functions and companies (mainly suppliers) the entire supply chain can be designed and managed towards improved logistics range as well as response flexibility. Considering DCs as defined in literature (Helfat et al., 2007), external collaboration constitutes a major capacity to create, extend and modify involved resources throughout the supply chain, for the purpose of achieving enhanced logistics flexibility. Overall, cross-functional interaction is an essential cornerstone of many identified DCs at a strategic level. The research results indicate that elements of a cross-functional orientation are present in all three types of DCs. In line with the traditional understanding of the SCM philosophy (Mentzer et al., 2001), logistics development spans functional and organisational borders, and the DCs for the creation of strategic logistics flexibility naturally have a similar profile (Manders et al., 2017; Stevenson \& Spring, 2007; Gligor \& Holcomb, 2014).

At a structural level, DCs are characterised by organisational means, i.e. the organisational design forms the major tool for how logistics flexibility can be enhanced. The organisation also plays an essential role for linking strategic level DCs, such as external collaboration, with operational DCs such as the continuous upgrading of operational logistics processes throughout the supply chain. The organisation therefore holds together DCs present at different hierarchical levels.

Structural sensing capabilities are mainly characterised by effective and efficient infrastructures for mutual information sharing between company functions and across company borders. Whereas traditional research normally emphasises market sensing practices where new opportunities are "discovered" via market intelligence (Kindström et al., 2013), or methods for environmental scanning (Hambrick, 1982), the structural sensing capabilities described in this study are instead geared towards joint, collaborative knowledge sharing among companies as well as individuals. In line with the emphasis on collaboration at the strategic level, mutual information exchange is therefore a decisive feature for the identified structural sensing capabilities. 
In line with flexibility research in general (e.g. Slack, 1987), a major theme for reconfiguring as well as seizing capabilities at a structural level is their attention to resource pooling in the physical flow of goods. The traditional logistics rationale of ensuring economies of scale and scope may be considered an underlying construct for range as well as response flexibility. While the pooling of resources enables increased preparedness for a variety of possible scenarios (i.e. increased range flexibility), it also enables improved response flexibility when pooled resources can be utilised for (more) rapid rearrangements and changes in the supply chain.

At an operational level, DCs are mainly characterised by their hands-on focus towards the existing logistics operations and the improvement of these. Sensing capabilities includes the management of a variety of formal KPIs, but also less formalised knowledge exchange practices among employees. Such rapid, often decentralised and informal, knowledge exchange constitutes an important input for reconfiguring as well as seizing capabilities.

Operational reconfiguring capabilities are mainly occupied with the challenge to predict future requirements on logistics performance and balance them towards existing requirements of logistics performance. Operational seizing capabilities are, in turn, characterised by the ability to rapidly upgrade existing logistics processes. This upgrading is made as a response to operational sensing capabilities. Short feed-back loops, whether based on KPIs or interaction among employees, are therefore decisive for seizing capabilities at an operational level.

\section{Conclusions}

In the current, rapidly changing business landscape, logistics flexibility is an essential ingredient for a company's ability to manage supply chain uncertainties and fulfil customer requirements. To sustain competitiveness over time, logistics flexibility should be coupled with DCs. This research has proposed a conceptual framework that connects the two dimensions of logistics range and logistics response flexibility to the three DC classes of sensing, seizing and reconfiguring, operating at strategic, structural and operational levels. DCs for the creation of logistics flexibility at a Swedish fast fashion retailer have also been identified and described as a means to further elaborate the characteristics of the DC classes.

\subsection{Research implications}

The research offers several managerial and theoretical implications, both with respect to the proposed framework itself and its application to empirical data. From a managerial point of view, the framework provides practical utility (Corely \& Gioia, 2011) by its systematic and comprehensive map of different DCs that underscore logistics flexibility. Covering different types of DCs at different hierarchical levels, the framework is an applicable, useful tool for understanding internally and externally oriented logistics development efforts regarding flexibility (Corley \& Gioia, 2011). Furthermore, the framework signals DCs to be present at different hierarchical levels in the company. For practitioners, this suggests that a DCV, which has so far been recognised as a highly strategic and theoretical lens (Barreto, 2010), can be viewed as a concept that permeates the entire logistics organisation. In essence, the findings show that logistics flexibility is created by DCs present at various organisational levels, including strategic and operational levels. Finally, another essential practical implication of the study is that the identified DCs 
from the case study can all be deliberately managed and shaped purposefully by companies, i.e. the current research thus indicates that DCs could be part of the managerial toolbox. For instance, deliberate investments can be made regarding knowledge-sharing routines with suppliers, and organisational practices can be changed to enhance resource pooling.

From a theoretical point of view, this research provides scientific utility by providing improved conceptual rigour regarding the relationship between the concept of logistics flexibility and a DCV (Corley \& Gioia, 2011). Although this relationship has previously been explored in research (Chiang et al., 2012; Griffith et al., 2006; Kim et al., 2013; Gligor \& Holcomb, 2014; Blome et al., 2013), this current research further details it by explaining how specific types of DCs (i.e. sensing, seizing and reconfiguring) underscore specific flexibility dimensions (range and response flexibility). This systematic and comprehensive combination offers a fruitful and solid knowledge base for logistics scholars concerned with flexibility research, as well as strategic management scholars interested in DCs. For logistics scholars, the research provides an understanding of the development processes that underscore logistics flexibility. Instead of a manufacturing flexibility perspective, which is the dominant starting point for existing logistics flexibility research, DCs here offer an alternative and valuable theoretical lens. In particular, this lens offers insights into how logistics flexibility can be proactively achieved, answering the recent call from e.g. Manders et al. (2017) for more research on the proactive facets of supply chain flexibility. This advances logistics flexibility research one step further, beyond the prevailing research which is mainly geared towards the "here and now" existence of logistics flexibility.

From a strategic management research point of view, the current research offers insights into the operationalisation of DCs. Despite - or perhaps as a result of - a rich conceptual discussion and massive research attention, research on DCs often remains at a conceptual level, which impedes the practical relevance of the field (Cordes-Berzinn, 2013; Barreto, 2010). Relating DCs to logistics flexibility here offers a way forward towards clarification of the "high-level" theory of dynamic capabilities. As well as conceptually aligning the two strands of literature, the research also applies the proposed framework to empirical data, thus bringing further knowledge regarding DCs in practice. For further operationalisation and contextualisation of dynamic capabilities, case studies indeed constitute a valuable research contribution (Barreto, 2010).

\subsection{Future research}

The research offers several future research areas in the intersection between logistics flexibility and a DCV. First, the data extracted from the single case study is limited and there is a need for further elaboration of the generic DC classes that includes an expansion into industries other than textile and fashion, as well as supply chain members other than retailers. From a methodology point of view, qualitative multiple case studies and quantitative survey research have the potential to make valuable contributions. In particular, qualitative case studies would be suitable for further knowledge generation regarding managerial attention towards the DCs that underscore logistics flexibility. In strategic management research, the presence of dynamic managerial capabilities, i.e. capabilities related to managerial decision-making, have long since been developed as a subcategory of DCs (Adner \& Helfat, 2003). So far however, this research has not been applied in logistics flexibility research, despite the fact that management involvement is essential for the creation of flexibility (Fayezi et al., 2017; Zhang et al., 2002). Future quantitative research could focus on items and scales for describing and measuring the 
DCs involved in the creation of logistics flexibility. Such research would form a promising complement to the research on how to measure the outcome of logistics flexibility, which has at least partly been dealt with in existing research (e.g. Swafford et al., 2006; Koste et al., 2004).

A second future research topic concerns logistics flexibility based on the supply chain as a unit of analysis. The current research has made a contribution by distinguishing DCs for the creation of logistics flexibility at different hierarchical levels within a focal company, but has ignored logistics flexibility at a supply chain level. As observed in other research (Manders et al., 2017; Stevenson \& Spring, 2007; Liao, 2020), logistics flexibility at a supply chain level largely remains to be researched. To expand existing research at the focal company level, future research could focus on the interplay between the levels. For instance, in relation to the results from the case study presented in this research, how do DCs of the retailer impact overall logistics flexibility in the supply chain, including the suppliers? In a similar vein, how do DCs for the creation of logistics flexibility at a supply chain level differ from those identified at a focal company level?

Finally, a third future research topic concerns the application of a knowledge management perspective to the DCs involved in the creation of logistics flexibility. Research on DCs contains a plethora of research related to knowledge creation and organisational learning that has been ignored in this piece of research. Future research could, for instance, focus on absorptive capacity (Zahra \& George, 2002) as an antecedent to logistics flexibility, or outline the learning mechanisms involved in the development of logistics flexibility.

\section{References}

Adner, R. and Helfat, C. (2003), "Corporate Effects and Dynamic Managerial Capabilities", Strategic Management J ournal, Vol. 24 No. 10, pp. 1011-1025

Barreto, I. (2010), "Dynamic capabilities: a review of past research and an agenda for the future", J ournal of Management, Vol. 36, 256-280.

Bernardes, E. and Hanna, M. (2009), "A theoretical review of flexibility, agility and responsiveness in the operations management literature - Toward a conceptual definition of customer responsiveness", International Journal of Operations \& Production Management, Vol. 29 No. 1, pp. 30-53.

Blome, C., Schoenherr, T. and Rexhausen, D. (2013), "Antecedents and enablers of supply chain agility and its effect on performance: a dynamic capabilities perspective", International J ournal of Production Research, Vol. 51 No. 4, pp. 1295-1318.

Christopher, M. and Holweg, M. (2011), "Supply Chain 2.0: managing supply chains in the era of turbulence", International J ournal of Physical Distribution \& Logistics Management, Vol. 41 No 1, pp. 63-82.

Christopher, M., Lowson, R. and Peck, H. (2004), "Creating agile supply chains in the fashion industry", International J ournal of Retail \& Distribution Management, Vol. 32 No 8, pp. 367-376 
Chiang, C.-Y., Kocabasoglu-Hillmer, C. and Suresh, N. (2012), "An empirical investigation of the impact of strategic sourcing and flexibility on firm's supply chain agility", International J ournal of Operations \& Production Management, Vol. 32 No. 1, pp. 49-78.

Cordes-Berszinn, P. (2013), “Dynamic capabilities: How organisational structures affect knowledge processes", London: Palgrave Macmillan.

Corley, K. \& Gioia, D. (2011), “Building theory about theory building: What constitutes a theoretical contribution?", Academy of Management Review, Vol. 36 No. 1, pp. 12-32.

Coughlan, P. and Coghlan, D. (2002), "Action Research for Operations Management", International J ournal of Operations \& Production Management, Vol. 22, No. 2, pp. 220240.

Defee, C. \& Fugate, B. (2010), “Changing perspective of capabilities in the dynamic supply chain era", The International J ournal of Logistics Management, Vol. 21 No. 2, pp. 180-206.

Eisenhardt, K.M. and Martin, J.A. (2000) "Dynamic capabilities: what are they?", Strategic Management J ournal, Vol. 21, pp. 1105-1121.

Fayezi, S., Zutshi, A. and O'Loughlin, A. (2017), “Understanding and development of supply chain agility and flexibility: a structured literature review", International J ournal of Management Reviews, Vol. 19 No. 4, pp. 379-407.

Flyvbjerg, B. (2006), "Five misunderstandings about case study research", Qualitative Inquiry, Vol. 12 No. 2, pp. 219-45.

Gerwin, D. (1993), “Manufacturing flexibility: a strategic perspective”, Management Science, Vol. 39 No. 4, pp. 395-410.

Gligor, D.M. and Holcomb, M.C. (2014), "The road to supply chain agility: an RBV perspective on the role of logistics capabilities", The International Journal of Logistics Management, Vol. 25 No. 1, pp. 160-179.

Gligor, D.M. and Holcomb, M.C. (2012), "Understanding the role of logistics capabilities in achieving supply chain agility: a systematic literature review", Supply Chain Management: An International J ournal, Vol. 17 No. 4, pp. 438-453.

Griffith, D.A., Noble, S.M. and Chen, Q. (2006), "The performance implications of entrepreneurial proclivity: a dynamic capabilities approach", Journal of Retailing, Vol. 82 No. 1, pp. 51-62.

Halldórsson, A. and Aastrup, J. (2003), "Quality criteria for qualitative inquiries in logistics", European J ournal of Operational Research, Vol. 144 No. 2, pp. 321-332.

Hambrick, D.C. (1982), "Environmental scanning and organizational strategy", Strategic Management Journal, Vol. 3 No 2, pp. 159-174.

Helfat, C., Finkelstein S., Mitchell W., Peteraf M.A., Singh H., Teece D., and Winter S., (2007), Dynamic Capabilities: Understanding Strategic Change in Organizations, Blackwell Publishing, New York.

Holweg, M. (2005), "The three dimensions of responsiveness", International J ournal of Operations \& Production Management, Vol. 25 No. 7, pp. 603-622. 
Huo, B., Gu, M. and Wang, Z. (2018), "Supply chain flexibility concepts, dimensions and outcomes: an organisational capability perspective", International J ournal of Production Research, Vol. 56 No. 17, pp. 5883-5903.

Ivanov, D., Das, A. and Choi, T.-M. (2018), "New flexibility drivers for manufacturing, supply chain and service operations", International J ournal of Production Research, Vol. 59 No. 10, pp. 3359-3368.

Jafari, H. (2015), "Logistics flexibility: a systematic review", I nternational J ournal of Productivity and Performance Management, Vol. 64 No. 7, pp. 947-970.

Ketokivi, M. and Choi, T. (2014), "Renaissance of case research as a scientific method", J ournal of Operations Management, Vol. 32 No 5, pp. 232-240.

Kim, M., Suresh, N.C. and Kocabasoglu-Hillmer, C. (2013), "An impact of manufacturing flexibility and technological dimensions of manufacturing strategy on improving supply chain responsiveness: business environment perspective", International J ournal of Production Research, Vol. 51 No. 18, pp. 5597-5611.

Kindström, D., Kowalkowski, C. and Sandberg, E. (2013), "Enabling service innovation: A dynamic capabilities approach", Journal of Business Research, Vol. 66 No. 8, pp. 10631073.

Koste, L.L., Malhotra, M.K. and Sharma, S. (2004), "Measuring dimensions of manufacturing flexibility", J ournal of Operations Management, Vol. 22, pp. 171-196.

Liao, Y. (2020), "An integrative framework of supply chain flexibility", International Journal of Productivity and Performance Management, Early cite, https://www.emerald.com/insight/publication/issn/1741-0401\#earlycite

Maclnnis, D. (2011), "A framework for conceptual contributions in marketing", J ournal of Marketing, Vol. 75, pp. 136-154

Manders, J.H.M., Caniëls, M.C.J . and Ghijsen, P.W.T. (2016), “Exploring Supply Chain Flexibility in a FMCG Food Supply Chain", J ournal of Purchasing and Supply Management, Vol. 22 No 3, pp. 181-195.

Manders, J., Caniëls, M. and Ghijsen, P. (2017), "Supply chain flexibility - A systematic literature review and identification of directions for future research", The International J ournal of Logistics Management, Vol. 28 No. 4, pp. 964-1026

March, J.G. (1991), "Exploration and exploitation in organizational learning", Organizational Science, Vol. 2 No. 1, pp. 71-87.

Mentzer, J.T., DeWitt, W., Keebler, J.S., Min, S., Nix, N.W., Smith, C.D. \& Zacharia Z.G. (2001), "Defining Supply Chain Management", J ournal of Business Logistics, Vol 22 No.

2, pp. 1-25.

Näslund, D., Kale, R. and Paulraj, A. (2010), "Action research in supply chain management - A framework for relevant and rigorous research, Journal of Business Logistics, Vol. 31 No. 2, pp. 331-355.

Olhager, J. (1993), "Manufacturing flexibility and profitability", International Journal of Production Economics, Vol. 30-31 No 1, pp. 67-78. 
Reichhart, A. and Holweg, M. (2007), "Creating the customer-responsive supply chain: a reconciliation of concepts", I nternational J ournal of Operations \& Production Management, Vol. 27 No. 11, pp. 1144-1172.

Rojo, A., Stevenson, M., Llorens Montes, F. and Perez-Arostegui, M. (2018), "Supply chain flexibility in dynamic environments - The enabling role of operational absorptive capacity and organisational learning", International Journal of Operations \& Production Management, Vol. 38 No. 3, pp. 636-666.

Sandberg, E. and Jafari, H. (2018), "Retail supply chain responsiveness - Towards a retail-specific framework and a future research agenda", I nternational J ournal of Productivity and Performance Management, Vol. 67 No 9, pp. 1977-1993.

Sharma, N., Sahay, B. and Sarma, S. (2017), "Supply chain agility: Review, classification and synthesis", International Journal of Logistics: Research and Applications, Vol. 20 No. 6 , pp. 532-559.

Singh, D., Oberoi, J. and Ahuja, I. (2013), "An empirical investigation of dynamic capabilities in managing strategic flexibility in manufacturing organizations", Management Decision, Vol. 51 No. 7, pp. 1442-1461.

Slack, N. (1987), "The flexibility of manufacturing systems", International J ournal of Operations \& Production Management, Vol. 7 No. 4, pp. 35-45.

Slack, N. (2005), "The changing nature of operations flexibility", I nternational J ournal of Operations \& Production Management, Vol. 25 No. 12, pp. 1201-1210.

Snyder, H. (2019), "Literature review as a research methodology: An overview and guidelines", Journal of Business Research, Vol. 104, pp. 333-339.

Stevenson, M. and Spring, M. (2007), “Flexibility from a supply chain perspective: definition and review", International J ournal of Operations \& Production Management, Vol. 27 No. 7, pp. 685-713.

Swafford, P., Ghosh, S. and Murthy, N. (2006), "The antecedents of supply chain agility of a firm: scale development and model testing", Journal of Operations Management, Vol. 24 No. 2, pp. 170-188.

Tiwari, A.K., Tiwari, A. and Samuel, C. (2015), "Supply Chain Flexibility: A Comprehensive Review" Management Research Review, Vol. 38 No 7, pp 767-792.

Teece, D., Pisano, G. and Shuen, A. (1997), "Dynamic Capabilities and Strategic Management", Strategic Management Journal, Vol. 18 No. 7, pp. 509-533.

Teece, D. (2007), "Explicating dynamic capabilities: The nature and microfoundations of (sustainable) enterprise performance", Strategic Management J ournal, Vol. 28, pp. 13191350.

Teece, D., Peteraf, M. and Leih, S. (2016), “Dynamic capabilities and organizational agility: Risk, uncertainty, and strategy in the innovation economy", California Management Review, Vol. 58 No. 4, pp. 13-35. 
Torraco, R. (2016), "Writing Integrative Literature Reviews: Using the Past and Present to Explore the Future", Human Resource Development Review, Vol. 15 No. 4, pp. 404428.

Upton, D.M. (1994), "The management of manufacturing flexibility", California Management Review, Vol. 36 No. 2, pp. 72-89.

van der Weerdt N.P., Volberda H.W., Verwaal E., Stienstra M. (2012), “Organizing for Flexibility: Addressing Dynamic Capabilities and Organization Design", In: Bøllingtoft A., Donaldson L., Huber G., Håkonsson D., Snow C. (eds) Collaborative Communities of Firms. Information and Organization Design Series, vol 9. Springer, New York.

Volberda, H. (1996), "Toward the flexible form: How to remain vital in hypercompetitive environments", Organization Science, Vol. 7 no. 4, pp. 359-374.

Volberda H. (1998), "Building the flexible firm; how to remain competitive", Oxford University Press, New York.

Wen, X., Choi, T.-M. and Chung, S.-H. (2019), "Fashion retail supply chain management: A review of operational models", International J ournal of Production Economics, Vol. 207, pp. 34-55.

Wohlin, C. (2014), "Guidelines for snowballing in systematic literature studies and a replication in software engineering", 18th International Conference on Evaluation and Assessment in Software Engineering. M. Shepperd. London, United Kingdom, Association for Computing Machinery.

Wolfswinkel, J., Furtmueller, E. and Wilderom, C. (2013), "Using grounded theory as a method for rigorously reviewing literature", European Journal of I nformation Systems, Vol. 22, pp.45-55.

Zahra, S.A. and George, G. (2002), "Absorptive capacity - A review, reconceptualization and extension", Academy of Management Review, Vol. 27, No. 2, pp. 185-203.

Zhang, Q., Vonderembse, M.A. and Lim, J.-S. (2002), "Value chain flexibility: a dichotomy of competence and capability", International Journal of Production Research, Vol. 40 No. 3, pp. 561-583.

Zhang, Q., Vonderembse, M.A. and Lim, J.-S. (2005), "Logistics flexibility and its impact on customer satisfaction", The International J ournal of Logistics Management, Vol. 16 No. 1, pp. 71-95. 